\title{
Muscle injury following laparoscopic appendectomy
}

\author{
Satoshi Ideno $\cdot$ Noriko Miyazawa $\cdot$ Shinichi Yamamoto
}

Received: 28 January 2014/ Accepted: 11 February 2014/Published online: 6 March 2014

(C) Japanese Society of Anesthesiologists 2014

Keywords Muscle injury · Head-down position . Laparoscopic surgery

To the Editor:

We describe a rare case of position-related muscle injury in a previously healthy 13-year-old boy (height $155 \mathrm{~cm}$; weight $45 \mathrm{~kg}$ ) undergoing laparoscopic appendectomy. The surgery was performed in supine position with the patient under general anesthesia and thoracic epidural analgesia. Duration of the laparoscopic procedure was 78 min. Patient positioning was in a head-down position as great as $30^{\circ}$. We carefully monitored the patient's position to avoid compressing his body. After emerging from anesthesia, he did not complain of surgical site pain or hip pain. However, he complained of severe left hip pain after $6 \mathrm{~h}$. The hip appeared to be swollen and tender. On postoperative day 3 , magnetic resonance imaging did not indicate other serious diseases, such as necrotizing fasciitis or rhabdomyolysis (Supplementary Fig. 1). The muscle pain was improved by conservative therapy.

Despite full-scale preparations for minimizing risk, position-related muscle injury occurred in a healthy pediatric patient. When a patient is in the head-down position, maintenance of limb perfusion is important to avoid position-related soft tissue injury [1]. Estimating from a simple model in a head-down position of $30^{\circ}$ (Supplementary Fig. 2), blood pressure around the hip drops about $1 / 5.44 \times$ (height, $\mathrm{cm}$ ) $\mathrm{mmHg}$ compared to that of the head. In pediatric cases, this pressure gradient could have a bad influence on limb perfusion because the normal blood pressure in children is lower than in adults. Additional intermittent measurement of blood pressure at the lower extremity could be effective for monitoring limb perfusion. If blood pressure in the lower extremity cannot be maintained, the anesthesiologist should consider intermittent reversal of the head-down position or limiting the duration of that position.

\section{Reference}

1. Halliwill JR, Hewitt SA, Joyner MJ, Warner MA. Effect of various lithotomy positions on lower-extremity blood pressure. Anesthesiology. 1998;89:1373-6.
Electronic supplementary material The online version of this article (doi:10.1007/s00540-014-1806-x) contains supplementary material, which is available to authorized users.

S. Ideno $(\bowtie) \cdot$ N. Miyazawa $\cdot$ S. Yamamoto

Department of Anesthesiology, Tokyo Metropolitan

Children's Medical Center, 2-8-29 Musashidai, Fuchu,

Tokyo 183-8561, Japan

e-mail: doctor_idebon@yahoo.co.jp 